\title{
Assessment of Nurses' Knowledge and Practices Regarding Care Of Patients With Diabetic Coma
}

\author{
Amany A.Abdelrahman ${ }^{1}$, Zeinab A.Mohammed ${ }^{2}$, Mervat A. Abdelaziz ${ }^{3}$ \& Mona Abd Elaziem Ahmed ${ }^{4}$. \\ 1. Specialist nursing at Elghanayem Hospital, Assuit, Egypt. \\ 2. Professor of Medical and Surgical Nursing, faculty of nursing, Assuit University, Egypt. \\ 3. Assistant professor of Critical Care and Emergency Nursing, Faculty of Nursing, Assuit University, Egypt. \\ 4. Lecturer of critical care and Emergency Nursing, faculty of nursing, Assuit University, Egypt.
}

\begin{abstract}
Diabetic coma is a dangerous condition that can lead to unconsciousness and even death. There are three main causes of diabetic coma: diabetic ketoacidosis, severe hypoglycemia and hyperglycemic hyperosmolar state. Aim of the study: This study aimed to assess nurse's knowledge and practice regarding patients with diabetic coma. Research design: A descriptive research design was utilized in this study. Sitting: This study was conducted in emergency Care Unit at Assuit University Hospital. Subject and Method: This study was carried out on a convenience 35 nurses who are working in emergency care unit. Tools: Tool 1: Nurses' knowledge assessment tool.Tool 2: Observational checklist regarding care for patient with diabetic coma. Results: The results showed that (68.6\%) of nurses had unsatisfactory level of knowledge regarding care of patient with diabetic coma and (94.3\%) of nurses had unsatisfactory level of practices regarding care for patient with diabetic coma. Conclusion: Nurses showed inadequacy of their knowledge regarding care of patients with diabetic coma. Recommendation: The study recommends that there is a need for an education program regarding care for patients with diabetic coma.
\end{abstract}

\section{Keywords: Assessment, Diabetic Coma, Practices, \& Nurse`s Knowledge}

\section{Introduction}

The management of Diabetic Coma in the first three hours becomes a medical emergency. A known diabetic presenting with coma may have Diabetic Ketoacidosis, Hyperglycemic Hyperosmolar state or Hypoglycemia. Diabetic coma can also present itself in a diabetic patient due to precipitating conditions like septicemia, acute myocardial infarction, stroke, acute liver injury and other hypoxic states. (Siddharth \& Shashank, 2015)

The main causes of coma occurring in people with diabetes are as a result of very low or very high blood glucose levels. The three most common causes of coma in people with diabetes are severe hypoglycemia, diabetic ketoacidosis and hyperglycemic hyperosmolar state. (Kotsakou, 2019) A quick diagnosis for diabetic coma can save the person's life. The cause of a diabetic coma is diagnosed using a number of tests including medical history, physical examination and blood tests including tests for glucose and ketone levels. (Baker, 2019)

Diabetic coma is a reversible form of coma found in people with diabetes mellitus. The three main causes of the diabetic coma is sever low blood sugar(hypoglycemia) in type 1 diabetes ,diabetic ketoacidosis(DKA), diabetic hyperosmolar (nonketotic)syndrome in type 2 diabetes.
Hypoglycemia occurs when you don't have enough glucose in your body .DKA occurs when your body uses fat instead of glucose for energy as a result of insufficient insulin. Diabetic hyperosmolar syndrome only occurs in type 2 diabetes. This condition occurs when your blood sugar is too high. (Elvira, et al., 2015)

If the blood sugar levels in the blood and brain drop to below normal, the risk of losing consciousness and falling into a diabetic coma is increased. Coma due to severe hypoglycemia is more likely to occur if a patient has taken a large overdose of insulin or other anti-diabetic medications, if alcohol is present in the system while the patient is hypoglycemic or if exercise has reduced the body supply of glycogen. (Ananya, 2019)

Diabetic Ketoacidosis (DKA) is a metabolic disorder consisting of three major abnormalities: elevated blood glucose level, high ketone bodies, and metabolic acidosis with an elevated anion gap. Coma that results from DKA is more common among people who are taking insulin for their diabetes. Common presenting symptoms include abdominal pain and the classic triad of hyperglycemia symptoms: polydipsia, polyphagia, and polyuria. Comas resulting from this condition are induced by a build-up of acidic compounds in the blood called ketones. 
which may occur if a person has missed an insulin dose .Ketoacidosis may also occur when the person has suffered an acute injury or infection, which can also alter hormone levels that counteract the effect of insulin.(Moudy, 2017)

Treatment of DKA includes administering isotonic intravenous fluids to correct dehydration and replacing lost electrolytes with sodium, potassium, magnesium, and phosphate supplements. Insulin is administered intravenously to reduce blood glucose and reverse ketoacidosis. (Ananya, 2019)

Coma which result from HHS are characterized by severe dehydration and very high blood glucose .Treatment includes rapid administration of insulin to bring down blood sugar levels and correction of dehydration using intravenous fluids .Fluids should be given at least 30 to 60 minutes before insulin. Electrolytes may be replaced and some patients need antibiotics for infection. (Erica, et al., 2015)

Caring for patients with diabetic coma requires knowledge about the disease process and prognosis. Patients with diabetic coma need to monitor vital signs, monitor laboratory studies, provide skin care, assess level of consciousness using GLASGOW COMA SCALE, assess for signs of infection, observe clients feet for ulcers, changing position every two hour and monitor intake and output. (Ketabchi, et al., 2016)

\section{Significance of the study}

The last statistical reports of patients with diabetic coma at assiut university hospital documented in (2018), was 3000 cases admitted to the medical emergency department. (Statistical Records of Assiut university Hospital, 2018)

Those patients need for special care to prevent any complication that may occur for them. Therefore this study will be conducted to assess nurses' knowledge regarding care for patients with diabetic coma.

Aim of the study

This study aimed to assess nurse`s knowledge and practices regarding care of patients with diabetic coma.

\section{Subjects \& Methods}

\section{Research questions:}

What is the level of nurse's knowledge and practice about patients with diabetic coma?

\section{Research design}

A descriptive research design was utilized in this study.

Setting

The study was conducted in emergency care unit at Assuit university hospital.

\section{Sampling}

all available nurses (35) working in emergency care unit.

Study tools

Two tools were used in this study

Tool 1: Assessment Nurses 'knowledge sheet regarding care of patient with diabetic coma:

This tool was developed by researcher after reviewing literatures to assess the knowledge level of critical care nurses regarding care for patient with diabetic coma. It translated into Arabic language. It consists of two parts

Part (1): Demographic characteristics of the study sample (age, marital status, educational level, years of experiences and previous training program)

Part (2): structured multiple choice and list questionnaire tool. (7)Multiple choice question and (7) list question covering:

Nurses` knowledge assessment related to diabetic coma included (14) questions and calculated (21) degrees.

Scoring system for nurse`s knowledge

For multiple choice questions, score value of (1) was awarded to each correct answer and zero (0) was allotted for wrong answer. For list questions, score value of (2) were awarded to done correctly answer and (1) was awarded for don incorrectly answer and zero (0) was allotted for wrong answer.

The total scores of nurse's knowledge was calculated and classified as follows

- Less than $60 \%$ was regarded as unsatisfactory level of knowledge.

- Equal or above $60 \%$ was regarded as satisfactory level of knowledge.

Tool 2: Observational checklist sheet regarding nursing care of patient with diabetic coma

This tool consisted of observational checklist sheet and developed by researcher after reviewing literatures for assessing nurse's practice regarding care of patient with diabetic coma.This tool covered all steps of all procedures of nursing care for patient with diabetic coma it includes

- Oropharngeal airway insertion which include ten steps

- Care for intubated patient which include eight steps

- Care for extubated patient which include five steps.

- Pulse oximetery which include four steps.

- Care for oxygen therapy which include seven steps .

- Arterial blood gases which include ten steps .

- Central venous measurement which include eight steps .

- Care for infusion pump which include eleven steps . 
- Care during blood transfusion which include eleven steps .

- Care during enteral feeding which include thirteen steps.

- Hygienic care which include seventeen steps .

- Oral care which include nine steps .

- Care during suctioning which included ten steps.

- Blood sugar test which included eight steps

- Gastric lavage which included fifteen steps .

- Insertion of urinary catheter which included twenty one steps .

- Electrocardiogram (ECG) which included seventeen steps .

- Care for patient with mechanical ventilation which included fourteen steps .

Scoring system for nurse`s practice. Each item was observed, categorized and scored as follow

1) Two for each step that was done correct (correctly, in time and with the required frequency).

2) One for each step done incorrect (incorrectly, not in time and without the required frequency).

3) Zero for step that note done.

The total score of nurse's practice was calculated and classified as follows:

-Less than $60 \%$ was regarded as unsatisfactory level of nurse's practice.

-Equal or above $60 \%$ was regarded as satisfactory level of nurse's practice.

Validity of the tool

The tool were revised by three (3) experts two (2)from critical care nursing staff and one (1) from medical and surgical nursing staff who reviewed the instrument for clarity, relevance, comprehensiveness, understanding and applicability. Recommended modifications were fulfilled.

\section{Reliability of the tool}

Reliability of the tool was assessed using alpha test to test the internal consistency knowledge $=0.788$

\section{Methodology}

Preparatory phase and administrative design

An official approval was obtained from the Dean of Faculty of Nursing, Assiut University to the head of the emergency care unit at Assiut University hospital, to carry out this study and explained the purpose of the study, and asking for permission to conduct it.

Field of work (Implementation phase)

The researchers started to collect data from the first of January 2018 until the end of March 2018. The researchers collect data from nurses who work in emergency care unit at Assiut university Hospital. All nurses were interviewed during break time (one hour) in different shifts or before beginning of shift.

\section{Ethical consideration}

Research proposal was approved from Ethical committee in the Faculty of Nursing at Assiut University. There is no risk for study subject during application of the research. The study will follow common ethical principles in clinical research. Confidentiality and anonymity will be assured. Study subject have the right to refuse to participate and or withdraw from the study without rational at any time. Study subject privacy will be considered during collection of data and agree to participant in this study (oral agreement).

Pilot study

A pilot study was carried out after the development of the tools. It was carried out not less than 10 nurses in working in an emergency care unit to test the reliability and applicability of the tool of the study. The necessary modifications were done based on the results of the pilot study. Those nurses were excluded from the subject of research work to assure the stability of answers and performances.

\section{Statistical analysis}

Date entry and data analysis were done using IBM SPSS 20.0 software. 


\section{Result}

Table (1): Frequency distribution for nurse`s socio-demographic characteristics of the studied nurses (n=35).

\begin{tabular}{|c|c|c|}
\hline Variable & No.(no=35) & $\%$ \\
\hline \multicolumn{3}{|l|}{ Age Group } \\
\hline $20-29$ years & 27 & 77.1 \\
\hline $30-39$ years & 5 & 14.3 \\
\hline 40-49 years & 3 & 8.6 \\
\hline Mean \pm SD (range) & \multicolumn{2}{|l|}{$27.45 \pm 7.73(20-48)$} \\
\hline \multicolumn{3}{|l|}{ Gender } \\
\hline Male & 5 & 14.3 \\
\hline Female & 30 & 85.7 \\
\hline \multicolumn{3}{|l|}{ Marital Status } \\
\hline Single & 13 & 37.1 \\
\hline Married & 22 & 62.9 \\
\hline \multicolumn{3}{|l|}{ Level of education } \\
\hline Nursing diploma & 10 & 28.6 \\
\hline Nursing Technical institute & 19 & 54.3 \\
\hline bachelor & 3 & 8.6 \\
\hline Technical health institute & 3 & 8.6 \\
\hline \multicolumn{3}{|l|}{ Experience year } \\
\hline Less than 1 year & 6 & 17.1 \\
\hline $1-5$ years & 13 & 37.1 \\
\hline $.5-10$ years & 7 & 20.0 \\
\hline $10-15$ years & 6 & 17.1 \\
\hline $15-20$ years & 2 & 5.7 \\
\hline More than 25 years & 1 & 2.9 \\
\hline \multicolumn{3}{|l|}{ Training courses } \\
\hline 1 course & 14 & 40.0 \\
\hline 2 courses & 10 & 28.6 \\
\hline 3 courses & 9 & 25.7 \\
\hline 4 courses & 2 & 5.7 \\
\hline
\end{tabular}

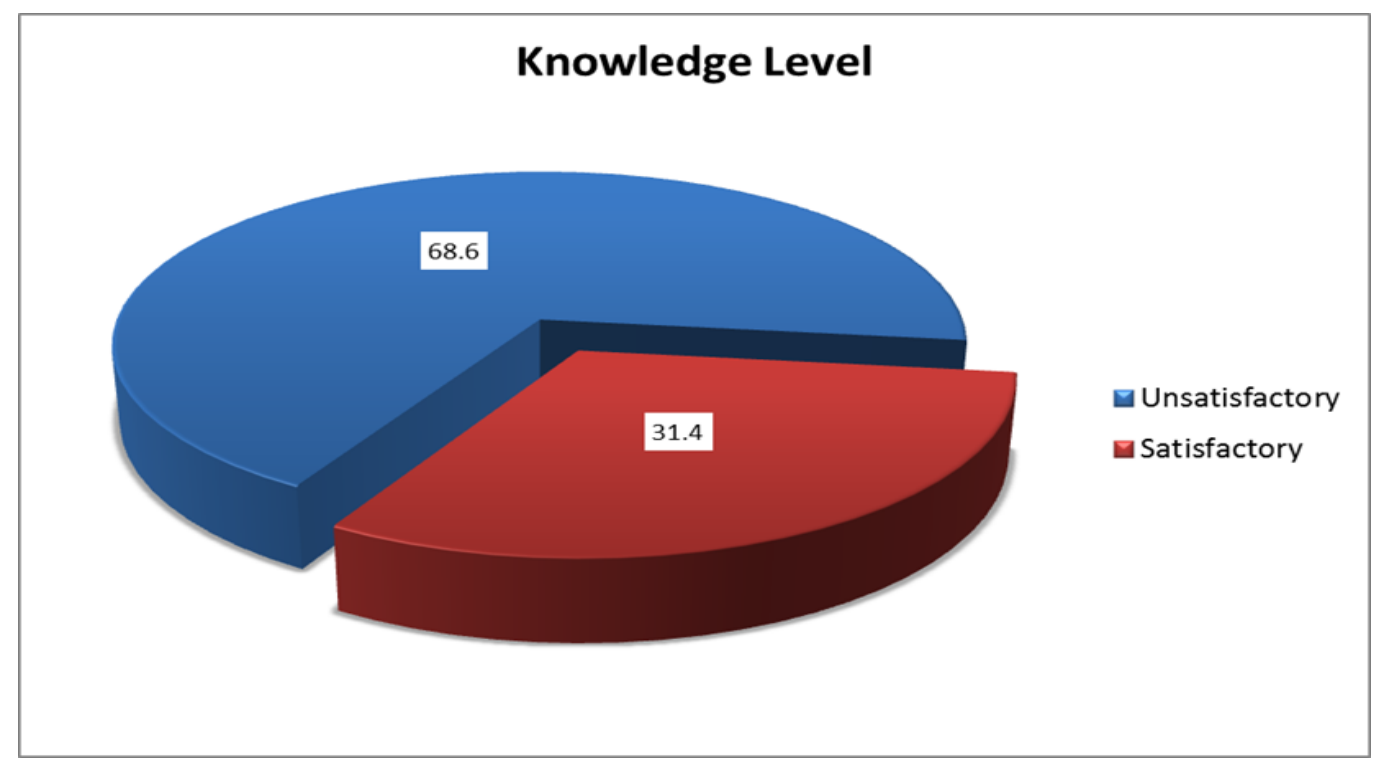

Figure (1): Distribution of nurses according to their knowledge about care of patients with Diabetic Coma for Study Sample $(n=35)$. 
Table (2): Distribution of nurses according to their knowledge about causes of diabetic coma.

\begin{tabular}{|l|c|c|}
\hline \multicolumn{1}{|c|}{ Causes } & Frequency & \% \\
\hline DKA & 17 & 48.57 \\
\hline Severe Hypoglycemia & 11 & 31.43 \\
\hline Hyperglycemic Hyperosmolar state(HHS) & 7 & 20 \\
\hline Total & $\mathbf{3 5}$ & $\mathbf{1 0 0}$ \\
\hline
\end{tabular}

Table (3): Distribution of nurses according to their knowledge about immediate care of patients with diabetic coma.

\begin{tabular}{|l|c|c|}
\hline \multicolumn{1}{|c|}{ Immediate care } & Frequency & \% \\
\hline Measuring random blood sugar & 13 & 37.14 \\
\hline Monitor vital signs & 10 & 28.57 \\
\hline Maintain airway patency & 7 & 20 \\
\hline Urine Test for Ketone & 5 & 14.29 \\
\hline Total & $\mathbf{3 5}$ & $\mathbf{1 0 0}$ \\
\hline
\end{tabular}

Table (4) Distribution of nurses according to their knowledge about Glasgow coma scale.

\begin{tabular}{|l|c|c|}
\hline Knowledge of glasgow coma scale use & Frequency & \% \\
\hline Eye response & 3 & 8.57 \\
\hline Verbal response & 7 & 20 \\
\hline Motor response & 15 & 42.86 \\
\hline Don't know & 10 & 28.57 \\
\hline Total & $\mathbf{3 5}$ & $\mathbf{1 0 0}$ \\
\hline
\end{tabular}

Table (5): Relation between total nurses' knowledge mean score and demographic characteristics $n=35$.

\begin{tabular}{|c|c|c|c|}
\hline & \multicolumn{3}{|c|}{ Knowledge Score About diabetic Coma } \\
\hline & $\mathbf{N}$ & Mean \pm SD & P .value \\
\hline \multicolumn{4}{|l|}{ Age Group } \\
\hline 20-29 years & 27 & $11.85 \pm 2.7$ & \multirow{3}{*}{0.338} \\
\hline $30-39$ years & 5 & $10 \pm 2.12$ & \\
\hline $40-49$ years & 3 & $11.33 \pm 0.58$ & \\
\hline \multicolumn{4}{|l|}{ Gender } \\
\hline Male & 5 & $12.4 \pm 1.67$ & 0.427 \\
\hline Female & 30 & $11.4 \pm 2.67$ & \\
\hline \multicolumn{4}{|l|}{ Marital Status } \\
\hline Single & 13 & $12.08 \pm 2.72$ & 0.350 \\
\hline Married & 22 & $11.23 \pm 2.47$ & \\
\hline \multicolumn{4}{|l|}{ Level of education } \\
\hline Nursing diploma & 10 & $10.9 \pm 1.45$ & 0.836 \\
\hline Nursing Technical institute & 19 & $11.79 \pm 2.9$ & \\
\hline bachelor & 3 & $11.67 \pm 4.73$ & \\
\hline Technical health institute & 3 & $12 \pm 1$ & \\
\hline \multicolumn{4}{|l|}{ Experience year } \\
\hline Less than 1 year & 6 & $13.17 \pm 2.79$ & \multirow{6}{*}{0.357} \\
\hline $1-5$ years & 13 & $11.85 \pm 2.76$ & \\
\hline $.5-10$ years & 7 & $11 \pm 2.45$ & \\
\hline $10-15$ years & 6 & $9.83 \pm 1.94$ & \\
\hline $15-20$ years & 2 & $11.5 \pm 0.71$ & \\
\hline More than 25 year & 1 & $12 \pm 0$ & \\
\hline Training courses & & & \\
\hline
\end{tabular}




\begin{tabular}{|l|l|l|l|}
\hline \multirow{2}{*}{} & \multicolumn{2}{|c|}{ Knowledge Score About diabetic Coma } & \multicolumn{1}{c|}{ Mean \pm SD } \\
\cline { 2 - 3 } & \multicolumn{1}{|c|}{$\mathbf{N}$.value } \\
\hline 1 course & 14 & $10.5 \pm 2.41$ & \multirow{3}{*}{0.227} \\
\hline 2 course & 10 & $12 \pm 2.58$ & \\
\hline 3 courses & 9 & $12.67 \pm 2.69$ & \\
\hline 4 courses & 2 & $11.5 \pm 0.71$ & \\
\hline
\end{tabular}

Table (6): Distribution of nurses according to their practices about care of patients with Diabetic Coma for Study Sample (n=35)

\begin{tabular}{|c|c|c|}
\hline \multirow{2}{*}{ Checklist Level } & \multicolumn{2}{|c|}{$(n=35)$} \\
\hline & No & $\%$ \\
\hline Unsatisfactory & 35 & 94.3 \\
\hline Satisfactory & 2 & 5.7 \\
\hline
\end{tabular}

Table (1): This table showed that $(77.1 \%)$ the most of nurses their age between (20-29) years, $(85.7 \%)$ of nurses were female and $(62.9 \%)$ of nurses were married. the majority of nurses $(54.3 \%)$ held technical institute of nursing Concerning their educational level. According to experience year about $(37.1 \%)$ of nurses had work experience between 1-5 years, and (2.9\%) had more than 25 years. In relation to their previous training courses about care of patient with diabetic coma this table revealed that $(40 \%)$ of them attended one course, $(28.6 \%)$ of them attended two courses, $(25.7 \%)$ of them attended three courses and $(5.7 \%)$ of them attended four courses.

Figure (1): It illustrate that about $68.6 \%$ of nurses have unsatisfied knowledge and $31.4 \%$ of nurses have a satisfied knowledge.

Table (2): This table showed that the most common cause of diabetic coma is DKA, about $(48.57 \%)$ of nurses said that the cause of diabetic coma is DKA,

Table (3): This table showed that $(37.14 \%)$ of nurses measuring random blood sugar to detect cause of diabetic coma and (14.29\%) assess ketone body in urine .

Table (4): This table showed that $(8.57 \%)$ of nurses consider that the glasgow coma scale use to assess diabetic coma by eye response verbal response, and motor response.

Table (5): It illustrate there is no significance differences in Relation between knowledge and age group, sex, level of education ,years of experience and training courses .

Table (6): It illustrate that about $94.3 \%$ of nurses have unsatisfied practice and $5.7 \%$ of nurses have a satisfied practice.

\section{Discussion}

According to this study the most of the nurses were of age group between (20-29) years. This result agree with result obtain from study done by Rohini, et al., (2019) This study showed that major of the nurses were female. This result agree with study conducted by Rohini, et al., (2019) who find that most of nurses were female. This study showed that the majority of the nurses were married. This finding was similar to the study conducted by Zeinab (2011) who find that majority of nurses were married.

According to this study the majority of nurses had nursing technical institute. this finding was similar to the study conducted by Batool, et al., (2013) which was indicated that the majority of nurses had nursing technical institute. This study showed that the majority of nurses have (1-5) years of experience. This result agree with study conducted by Batool, et al., (2013) which was indicated that the majority of nurses have (1-5) years of experience.

This study showed that the majority of nurses attended one training course. This result agrees with study conducted by Ali, et al., (2013) which indicated that the majority of nurses attended one training course.

Regarding to nurses' knowledge mean score about care of patient with diabetic coma for nurses, the study results revealed that there was highly statistical difference with between knowledge levels and the majority of nurses have boor knowledge. This result disagrees with study conducted by Sachin, et al (2019) which was indicated that the majority of nurses have good knowledge.

This study showed that most of nurses said that the cause of diabetic coma is DKA, thirty present of them said that severe hypoglycemia and twenty present said that the cause of diabetic coma is HHS by measuring random blood Sugar, monitor vital signs, maintain airway patency and assess if there ketone body in urine.

In current study minor of nurses not know the use of Glasgow coma scale while majority of them know the use of Glasgow coma. This result agrees with study conducted by Balsam, (2014) which was indicated that less than one third minor of nurses not 
know the use of Glasgow coma scale while more than sixty present of them know the use of Glasgow coma scale.

According to the present study findings, there is no significance between socio demographic data and total nurse's knowledge and this result disagree with study conducted by Rohini, et al., (2019) which was indicated there highly significance between socio demographic data and total nurse's knowledge.

Lastly, the finding of the present study revealed major deficiencies in skills of nurses regarding care of patients with diabetic coma and this result agree with the result conducted by Zeinab (2011) which was indicated there a highly deficiencies in nurses skills regarding care of patient with diabetic coma.

\section{Conclusions}

Based on the result of the present study, it can be concluded that:

The majority of nurses have poor knowledge regarding care for patient with diabetic coma. This study aimed to assess nurse's knowledge and practices regarding care of patients with diabetic coma.

\section{Recommendations}

Based on results of the present study the following can be recommended

1. Continued nursing education and training programs in emergency care unit should be well organized at Assiut university hospital.

2. Nurses should add to their routine obligations the regular reading of up-to-date references (periodical, textbooks, etc.). They should always be encouraged to attend scientific meetings and conferences to keep pace with the rapidly growing wealth of knowledge and practice necessary for proper nursing service.

3. Nurses in emergency care units are required to successfully complete a test of basic knowledge before assuming independent responsibility for patient care.

4. Encourage nurses for self-education to improve their knowledge to reduce the complications.

5. Provide nurses with periodic training sessions and evaluations to improve and assess their knowledge regarding care of patient with diabetic coma.

\section{References}

1. Abduelmula R., \& Hawa J., (2013): Assessment of diabetes-related knowledge among nursing staff in a hospital setting, Unpublished Master thesis.

2. Ananya, (2019): Diagnosis of diabetic coma ,Nursing Journal of India,Vo.(4) No(3) pp.2-5
3. Arletha C., (2016): The Impact of Diabetes Education on Nurses' Knowledge of Inpatient Diabetes Management, Unpublished Master thesis.

4. Balsam G., (2014): Assessment of nurse's knowledge regarding care of unconsciousness patients, Un published Master thesis in El-mak Nimer university hospital.

5. Batool A., Widad K., \& Ali D., (2013): Assessment Of Nurse's Knowledge Concerning Glasgow Coma Scale In Neuro Surgical Wards, Journal of Kufa for Nursing Sience Vol. (3)No.(2)

6. Doug Elliott, Leanne Aitken and Wendy Chaboyer, (2018): CRITICAL CARE NURSING, 2 nd edition,chapter5, Australia: Elsevier

7. Elhagga I., (2016): Impact of an educational program for nurses knowledge and practice about glasgow coma scale, International Journal of Recent Scientific Research Vol.(7) No.(3)

8. Evans K., Thompson J., Spratt S., Lien L., Vorderstrasse A., (2014): The Implementation and evaluation of an evidence-based protocol to treat Diabetic ketoacidosis: a quality improvement study, Adv Emerg Nurs J Vol. (3).No (2) http://www.diabetes.co.uk/diabetescomplicatons/diabetic -coma.html

9. Hashmi S., Giri P., \& Shafee M., (2017): Study of risk factors of type 2 diabetes mellitus in the field practice area of rural health training centre ,Un published Master thesis of IIMSR Medical College, Badnapur, Jalna, Maharashtra,Ind J Forensic Community Med.

10. International Diabetes Federation (IDF), (2017): IDF Diabetes Atlas, 8th edition,( pp1-43) Available at http://diabetesatlas.org/resources/2017atlas.html. Accessed 20 May 2018.

11. International Diabetes Federation (IDF). (2017): IDF Diabetes Atlas. 8th edition, pp143Available at http://diabetesatlas.org/resources/2017-atlas.html. Accessed 20 May 2018

12. Park, K, (2017): Text Book of Preventive and Social Medicine, 24th edition, chapter 4, pp. 412 Jabalpur: Banarsidas-Bhanot

13. Rohini S., (2019): Study to assess the knowledge regarding diabetes management amongst medical intern and nursing staff in tertiary care teaching hospital in Marathwada region of Maharashtra, India, International Journal of Advances in Medicine Vol.(6) No.(2)

14. Siddharth, \& Shashank, (2015): The management of diabetic coma , International Journal of Advances in MEDICINE Vol.(3) No (2) 
15. WHO, World Health Day: Beat diabetes, (2016): Available at: www.who.int/campaigns/worldhealthday/2016/event/en/. Accessed 10 June 2018.

16. Zeinab A., (2011): Health and Knowledge Progress among Diabetic Patients after Implementation of a Nursing Care Program Based on Their Profile, Journal of Diabetes and Metabolism Vol.(2)No.(2) 